\title{
Industry 4.0 and Technology Adoption in The Garment Industry
}

\author{
Luthfina Ariyani ${ }^{1}$, Wati Hermawati ${ }^{1}$, Trina Fizzanty ${ }^{1}$, Ardanareswari Ayu Pitaloka ${ }^{1}$, \\ Andi Budiansyah ${ }^{1, *}$
}

\author{
${ }^{1}$ Research Center for Science, Technology, and Innovation Policy and Management, Indonesian Institute of Science, \\ Jakarta 12710, Indonesia \\ *Corresponding author. Email: luthfina.ariyani@gmail.com
}

\begin{abstract}
Industry 4.0 is a major change that occurs in the manufacturing industry where the application of internet-based technology and information technology is key in forming a value chain network. This study aims to explore the application of industry 4.0 in the perspective of technology adoption theory, with a qualitative approach to five garment companies in Indonesia. Application of Industry 4.0 is seen in two aspects, namely technology for production and management, and TechnologyOrganization-Environment (TOE) Framework is used as a reference in analysing the factors that influence companies in adopting industry 4.0. The results of this study indicated that Indonesian garment companies have done a considerable technological transformation into more sophisticated direction. Adoption of new production machines, improvement in software systems, and the new and improved construction of factories that lead to the use of more modern technology were conducted at firm level. However, in general there are no companies that completely deploy industry 4.0. Several factors were identified as the determinants to this adoption process; in the technological context it consists of benefits and costs consideration; in the organizational context, it includes management support and workforce competence; while in the environmental context it consists of the product life cycle, global competition, and government support.
\end{abstract}

Keywords: Technology Adoption, TOE Framework, Industry 4.0, Garment Industry

\section{INTRODUCTION}

Technological developments have entered the fourth industrial revolution era, which began with the introduction of the term "Industry 4.0" by Germany in 2011 and brought a significant impact on industrial world [1]-[4]. Industry 4.0 is described as a major change that have taken place in the manufacturing industry through the further development of sophisticated internet-based information technology; resulting in high flexibility system, enabling costefficiency (e.g. quality control cost, maintenance cost, and inventory cost), increasing productivity, reducing time-to-market, promoting ergonomic design and accuracy in forecasting, as well as integrating production facilities, supply chains, and service systems within a value chain network [4]-[6].

Along with these significant promising benefits, the adoption of industry 4.0 has subsequently grown in many industries in various countries, including Indonesia. The Indonesian government rolled out the Making Indonesia 4.0 Program on April 2018 aiming at revitalizing the manufacturing sector in Indonesia, one of which, was through the adoption of industry 4.0 [7]. This program is largest economy in the world by 2030 [7]. Making expected to be able to increase global competitiveness and global export market share of Indonesia's manufacturing sector, that encouraging Indonesia to become the $10^{\text {th }}$ Indonesia 4.0 further assigned 5 manufacturing sectors as pioneers in implementing industry 4.0 , one of which is the textile and textile product (TPT) sector, including garment sector. This sector is considered have good economic contribution to the country as well as ready for adopting industry 4.0[7].

Nevertheless, the adoption of industry 4.0 in Indonesia is not without obstacles; the concept of industry 4.0 is still new and adoption of industry 4.0 is still lacking as well as quite challenging for the manufacturing sectors in Indonesia, particularly before pandemic COVID-19 outbreak in Indonesia. Therefore, this study aims to understand industry 4.0 adoption in Indonesia, more precisely within the garment manufacturers. The adoption is explored in two ways. First, this study explores the extent to which industry 4.0 adoption is carried out in Indonesia garment industry. Second, this study identifies 


\section{Procedia Business and Financial Technology}

Proceedings of the 2nd International Conference on Business and M anagement of T echnology (ICO N BM T 2020) - Part 2

influencing factors industry 4.0 adoption within garment manufacturers.

This study provides specific insight at the company contexts related to industry 4.0 adoption, so that this could be a comparative reference at the adoption level in any different context. In addition, this research could also be a useful insight for garment manufacturers and decision makers in understanding industry 4.0 phenomena in Indonesia and become a basis for consideration in developing proactive interventions in order to support technological transformation, especially in the context of the Indonesian garment manufacturers.

\section{THEORITICAL FRAMEWORK}

According to the objectives, we proposed theoritical framework in two concepts. Specific concept of apparel industry 4.0 proposed by Gökalp, Gökalp, \& Eren [8] is used to explore to what extent the indusry 4.0 adoption occur in garmen manufacturer. Identification of influencing factors adoption conducted based on Technology- Organization-Environment (TOE) Framework proposed by Tornatzky \& Fleischer in [9].

\subsection{Apparel Industry 4.0}

According to the objectives, we proposed theoritical framework based on Gökalp, Gökalp and Eren [8], the adoption of industry 4.0 in garmen company is divided into two aspects; those are technology for production and technology for management.

\subsubsection{Technology for Production}

Garment production process generally consists of designing, prototyping, cutting, sewing, ironing, quality controling, packaging, and shipping processes. The utilization of industry 4.0 encompassing production process is as follows.

a. Utilization of virtual reality technology and 3D printers for in product design and product prototyping.

b. Utilization of augmented reality and kinect technology in sewing for increasing productivity and efficiency as well as reducing number of defective products.

c. Utilization of image processing and machine learning for quality controlling to reduce humanerrors.

d. Utilization of sensors and big data-based applications for predictive maintenance needs.

e. Utilization of robotic technology for material handling, cutting processes, and packaging.

\subsubsection{Technology for Management}

Some industry 4.0-related technologies that used in $30 / 180$ garment company are as follows.

a. End-to-end digital integration by utilizing IoT technology, big data application, and cloud systems.

b. Utilization of RFID (Radio Frequency Identification) technology to track product status in production lines and buyer order status.

c. Utilization of sensors and big data-based applications for production planning activities, employee performance management, supplier performance management, warehouse management, and monitoring production line performance to identify bottlenecks and formulate corrective strategies.

d. Utilization of robotic technology reduce labor intervention (e.g. for warehouse management).

\subsection{TOE Framework}

This study uses TOE Framework as the basis in understanding the influencing factors towards industry 4.0 adoption, due to the reason that TOE Framework provides a more holistic perspective in seeing how technology adoption is carried out. The TOE Framework reviews the technology adoption process at the company level as a whole by looking at three main contexts, namely technology, organization, and the environment that influence the process in which a company adopts and accepts the technology (Lippert \& Ph, 2006). The first context is the technological context, which related to company's assessment of the perceived benefits of the related technology; the second context is the organizational context which related to company's perception of the organizational resources availability to adopt related technology; while the third context referred to the environmental context which related to company's perception of the pressure from outside the company that encourages the company to adopt the related technology [10], [11]. Figure 1 illustrate the framework used in this study consisting the use of Garment Industry 4.0 Concept and three context of TOE Framework.

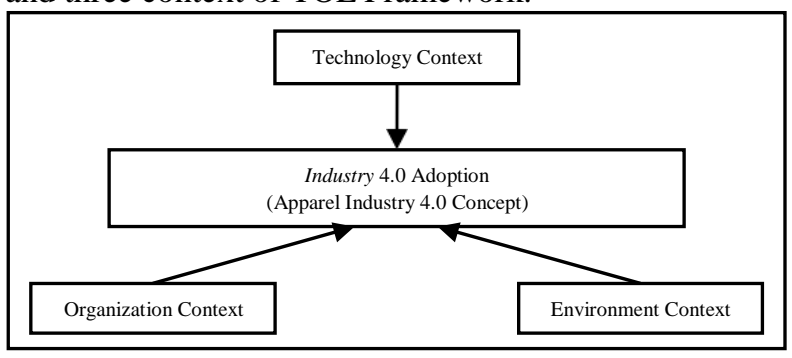

Figure 1 Theoritical Framework

\section{RESEARCH METHOD}

This study uses a qualitative descriptive approach based 


\section{Procedia Business and Financial Technology}

Proceedings of the 2nd International Conference on Business and M anagement of T echnology (ICO N BM T 2020) - Part 2

on case studies in five garment companies in Indonesia. The data were collected through several approach, such as:

a. Interviews with top and middle managers of five garment companies in Central Java and Banten, as well as with two representatives from the Indonesian Textile Association (API) in Jakarta.

b. Direct observation to the four production facilities of garment companies in the Central Java.

c. Focus Group Discussion (FGD), attended by 2 representatives of the Ministry of Trade Republic of Indonesia, 4 representatives from 3 garment companies, 1 representative from API, 1 representative from the Bandung Textile Engineering College (STTT), 3 representatives from STTT Alumni Association, and 2 representatives of garment production equipment providers.

\section{RESULT AND DISCUSSION}

\subsection{Indonesian Garment Manufacturers Industry 4.0 Adoption}

Generally, most of Indonesia's garment manufacturers have been transforming its technology toward more sophisticated ones. This is indicated by the installation of new production machines, upgrading software systems, and even the construction of new factories that lead to the use of more modern technologies that have considered the use of environmentally friendly energy. The following is an explanation of the development of garment company technology in the context of industry 4.0.

\subsubsection{Production Technology}

Referring to Gökalp, Gökalp and Eren [8], this study identifies that companies have applied several industry 4.0 technologies for production activities. In most companies, the process of drawing patterns has been done using software that is able to maximize the use of fabric. In addition, the transfer of product pattern cutting data to the cutting machine has also been done in a computerized manner. Most companies have also used laser cutting machines. Furthermore, the company has also implemented automated fabric spreading machine technology.

On the other hand, the product design and rendering process has been carried out using 3D applications. The company has a special unit to make product prototypes using sewing machines, but there is no use of virtual reality technology or $3 \mathrm{D}$ printers in this process. However, the quality control process is still done manually by human workers, even though there are companies that already have a vision to develop image processing technology for quality control needs.
All companies involved in this study also have not carried $31 / 180$ out the process of taking and processing further data from production machines, so there is no utilization of production data for analytical needs such as predictive maintenance processes.

Furthermore, the sewing process is still carried out by workers using electrically powered sewing machines. There is no further use of technology such as the use of virtual reality and kinect technology for the sewing process. However, although [8], [12], [13] mention that there are technological developments in the sewing process, [12],

[13] also recognize that the sewing process is not can be done automatically because the process has a fairly high level of complexity. The company also feels the same. Griez \& Lutz [13] states that the sewing process still relies on highly skilled personnel to carry out operations manually. Compared to the cutting process, the development of automation for the sewing process is still in the primitive stage, with only a small number of automatic configurations of the sewing process possible [12].

In addition though in theory Gökalp, Gökalp, \& Eren [8] did not mention the special industry 4.0 requirements for production machines other than sewing machines, but the result of observation in this study found that the company had also transformed its machine technology to become more automatic so as to increase productivity, even though it still used human power to operate it. This automation for example is in the process of mounting buttons and installing pockets. Increased productivity can be seen in the ability of work done by each worker at one time. One worker who previously could only do one work process at a time, with the installation of this new machine, was able to do two types of work at a time.

\subsubsection{Management Technology}

The technological level for managerial activities, several companies have implemented systems integrated internally and externally with consumers and suppliers. However, some only utilize the integrated system internally. Furthermore, this internal integration has not yet fully integrated all company's business processes, especially in the production area.

In addition, there are companies that have used RFID technology for product tracking needs during both the production and shipping processes. This makes it easier for both companies and buyers to identify the order status. As mentioned previously, the company has not applied technology for the process of data collection in the company's activities and has not carried out further analysis of the data through the use of big data analysis such as line balancing analysis and production planning analysis in real time.

The above description shows that although each company 


\section{Procedia Business and Financial Technology}

Proceedings of the 2nd International Conference on Business and M anagement of T echnology (ICO N BM T 2020) - Part 2

has a different level of development and technological capabilities, in general there are no companies that make full use of industry 4.0 technology. In addition, the lack of connectivity and integration shows that current technological developments in the garment industry are still leading to the level of automation. Whereas in industry 4.0, integrated information both vertically, horizontally, and end-to-end is one of the advantages of utilizing key industry

4.0 technologies such as the Internet of Things (IoT) and cyber physical systems (CPS) [14].

\subsection{Determinant Factors of Technology Adoption in Garment Companies}

\subsubsection{Technology Context}

\section{Benefits Perceived}

Context of technology in this research identifies that the benefit factor offered by technology becomes a very important factor for all companies in deciding to adopt technology. These benefits are in the form of increased speed and ease. For example, the use of shirt folding machines, button mounting machines, and pocket and collar mounting machines adopted at the company aims to make the previously complex sewing process faster and easier.

Another benefit felt by the company is in the form of increased flexibility, given the high flexibility function is needed in the garment business which is very perishable. For example, the high flexibility function found in fabric cutting machines today, has been able to do fabric cutters in small quantities, from previously only able to do cuts in large quantities. So companies can easily produce products with different models even with a small lot size. In addition, the benefits of installing a new machine are in terms of increased accuracy and efficiency. For example the use of laser cutting machines can improve accuracy in the cutting process and the use of computerized design applications has helped companies in the process of making patterns so that the use of fabric can be maximized and automatically reduces the amount of fabric wasted. That is, increasing productivity is also a benefit that companies consider in adopting technology. For example, with the use of the latest pocket mounting machine, one worker can carry out a pocket mounting process that produces two outputs at a time, from the previous one output at atime.

Therefore the perceived benefits of using technology have a positive impact on technology adoption. The more significant the benefits offered by technology, the greater the tendency for companies to implement it.

\section{Cost}

This study also identifies determinants in terms of costs incurred for investment in technology that affect $32 / 180$ companies in adopting the technology, or which makes technology adoption less than optimal. For example, there are garment companies that actually have production machines that are able to connect to productivity monitoring devices such as through smartphones. However, this function cannot be maximized due to the consideration of operational costs that must be incurred by the company.

In addition, technology adoption decisions are based on consideration of business feasibility. When the investment is considered profitable, the technology will be applied. But on the contrary if the technology investment is considered not feasible, for example when labor costs are still far cheaper than the investment costs of adopting new technologies, then the company will continue to apply the old technology.

Therefore, technology investment costs become a factor that needs full consideration for companies in adopting industry 4.0 technology. The higher the cost of technology investment, the tendency is the lower the possibility of companies to adopt the technology, unless market demand for the product requires the use of the technology, both for reasons of efficiency and improvement in quality and productivity.

\subsubsection{Organization Context}

\section{The Role of Management}

The role of management becomes important in determining the adoption of technology in the company. Most significant technological changes that occur in the company have the full support of the leadership and the technology change agenda is made an important part of the company's business strategy. In this case management has the capacity to determine the direction of company change and encourage the will and change of workers.

The support and clear direction of management for technological change determine the success of the transformation process. Conversely, less optimal support or less concrete direction of change makes the transformation process hampered.

\section{Employee Competency}

Employ6ee competence becomes an important consideration in deciding the adoption of technology, because technological transformation inevitably also demands changes in employee competencies. The change is in relation to the increasing need for workers with higher expertise, especially in the aspect of utilizing technology for analytical needs.

One of the advantages in implementing Industry 4.0 is that the company has abundant business process data and is updated in real time so that it can be used for analysis needs in decision making. As stated by Schwab and Samans [15] that along with technological transformation 


\section{Procedia Business and Financial Technology}

Proceedings of the 2nd International Conference on Business and M anagement of T echnology (ICO N BM T 2020) - Part 2

by companies, the company's ability to produce data will also increase, so the ability to work with data and make data-based decisions will become increasingly vital skills. Therefore, if the technological transformation is not matched by an increase in the ability of human resources, then the potential benefits to be gained from the technological transformation will not be maximized.

\subsubsection{Environment Context}

\section{Product Life Cycle and Customization}

Technology transformation in garment companies is driven by the short life cycle of fashion products. Changes in the dynamics of the fashion industry have forced retailers to minimize costs and increase flexibility in design, quality, and time-to-market speed as a key strategy to maintain a profitable position in an increasingly competitive market [16]. The impact is that the production process is faster, including garment companies in Indonesia which have many global fashion product retailers so that the adoption of technology is done to maintain competitiveness through accelerating the production process and increasing productivity. Pedersen et al. [17] explained that current production is undergoing a paradigm shift from a mass production system to a mass customization system. This means that technology adoption is needed so that more product variations, shorter life cycles, and smaller batch sizes.

2. The intensity of Competition in the Global Market Indonesia holds a large global garment market with very high competition. The biggest competitors are Vietnam and China, which benefit greatly because it is geographically more strategic, with high technology transformation so their lead time delivery is shorter than Indonesia. Therefore, technology adoption is vital to encourage competitiveness in the global market.

\section{Government policy}

The Government of Indonesia through the Ministry of Industry as the leading sector issued the Making Indonesia 4.0 program which aims to revitalize the manufacturing industry which aims to increase industrial productivity, global competitiveness, and encourage the market of Indonesian products in the global market [7]. An example is a program consisting of fiscal incentives for industries that use high technology and cross-sector collaboration such as with universities.

However, the technological transformation will increase productivity, threaten the existence of workers, and be replaced by workers with high competence in the field of technology. The rationalization of workers is an automatic cycle that occurs in the production system when new technology is adopted so that there is an adjustment in the competence of workers and the replacement of human labor into high-tech machine power. The need for labor will remain if the market share increases so that the production line increases. But still with the adjustment of competence. That is, if the market share does not increase, then high technology is also not needed.

Based on the description of the determinants of industry technology adoption 4.0, the factors are mapped into the framework in Figure 2 below.

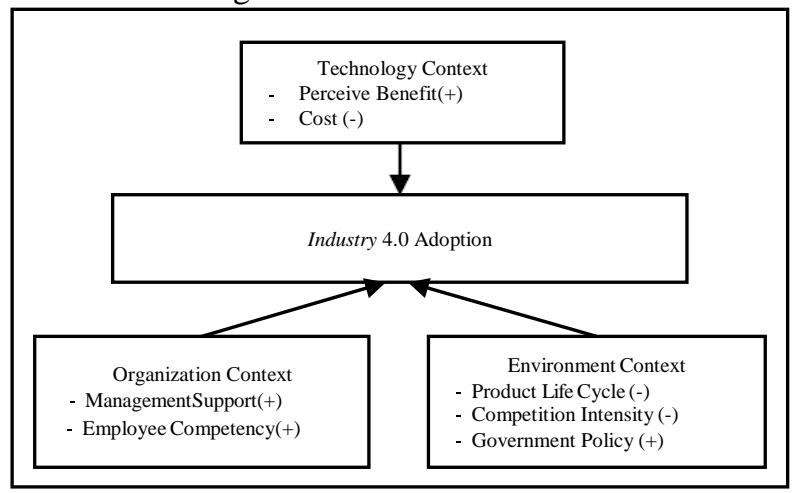

Figure 2 Determinant Factors of Industry 4.0 Adoption in Indonesian Garment Manufacturers

\section{CONCLUSION}

The Garment Industry in Indonesia is currently in the process of transforming technology which is demonstrated through the installation of new production machines, upgrading software systems, and even though the construction of factories that lead to the use of more modern technology. Although there is no 4.0 technology implementation that can be seen from the lack of connectivity and integration in the production system, automation already exists. However, the most important thing to do is integration and data processing in production and management systems as well as increased collaboration with universities, vocational schools, and research institutions.

In addition, the government needs to provide support in the form of investment in research and development and encourage the expansion of global markets through global economic and trade cooperation agreements, also needs to encourage upgrading the skills of workers to match skills requirements in the use of industry 4.0.

\section{ACKNOWLEDGEMENT}

This research was conducted in 2019 as part of research entitled The Role of the Global Value Chains of the Indonesian Garment Industry in Supporting the Application of Technology 4.0 conducted and funded by the Research Center for Science, Technology, and Innovation Policy and Management - Indonesian Institute of Sciences. We are very grateful to all resource persons 


\section{Procedia Business and Financial Technology}

Proceedings of the 2 nd International Conference on Business and M anagement of T echnology (ICO N BM T 2020) - Part 2

from all companies, government institutions and association.

\section{REFERENCE}

[1] D. Horváth and R. Z. Szabó, "Technological Forecasting \& Social Change Driving forces and barriers of Industry 4 . 0: Do multinational and small and medium-sized companies have equal opportunities ?," vol. 146, no. June, pp. 119-132, 2019.

[2] A. H. Jantan, H. B. Hashim, C. W. Chong, M. M. Abdullah, A. Bakar, and A. Hamid, "FOURTH INDUSTRIAL REVOLUTION IN DEVELOPING COUNTRIES : A CASE ON," vol. 21, no. 1, pp. 19, 2018.

[3] J. Qin, Y. Liu, and R. Grosvenor, "A Categorical Framework of Manufacturing for Industry 4.0 and beyond," Procedia CIRP, vol. 52, pp. 173-178, 2016.

[4] A. Ustundag and E. Cevikcan, Industry 4.0: Managing The Digital Transformation, no. September. 2018.

[5] P. Schönsleben, F. Fontana, and A. Duchi, "What Benefits do Initiatives Such as Industry 4.0 Offer for Production Locations in High-wage Countries?," Procedia CIRP, vol. 63, pp. 179-183, 2017.

[6] P. Caylar and O. Noterdaeme, "Digital in industry : From buzzword to value creation," no. Exhibit 1, pp. $1-9,2016$.

[7] Kementerian Perindustrian, "Making Indonesia 4.0," 2018.

[8] E. Gökalp, M. O. Gökalp, and P. E. Eren, "Industry 4.0 Revolution in Clothing and Apparel Factories: Apparel 4.0," Ind. 4.0 from MIS Perspect., no. December 2018, pp. 169-183, 2018.

[9] Y. K. Dwivedi, M. R. Wade, and S. L. Schneberger, "Informations Systems Theory: Vol.2," Springer, vol. 28, no. September 2011, p. 461, 2012.

[10] K. K. Y. Kuan and P. Y. K. Chau, "A perceptionbased model for EDI adoption in small businesses using a technology \pm organization \pm environment framework," vol. 38, 2001.

[11] S. K. Lippert and D. Ph, "Technological , Organizational, and Environmental Antecedents to Web Services Adoption," vol. 6, no. 1, 2006.

[12] M. Suh, "Automated cutting and sewing for industry 4.0 at ITMA 2019," J. Text. Apparel, Technol. Manag., vol. 11, no. 1 Special Issue, pp. 1-13, 2019.

[13] T. Gries and V. Lutz, Application of robotics in garment manufacturing. Elsevier Ltd, 2018.

[14] H. Kagermann, W. Wahlster, and J. Helbig, "Securing the future of German manufacturing industry: Recommendations for implementing the strategic initiative INDUSTRIE 4.0," Final Rep. Ind. 4.0 Work. Gr., no. April, pp. 1-84, 2013.
[15] K. Schwab and R. Samans, "Global Challenge Insight Report: The Future of Jobs," World Econ. Forum, no. January, pp. 1-167, 2016.

[16] V. Bhardwaj and A. Fairhurst, "Fast fashion: Response to changes in the fashion industry," Int. Rev. Retail. Distrib. Consum. Res., vol. 20, no. 1, pp. 165-173, 2010.

[17] M. R. Pedersen et al., "Robot skills for manufacturing: From concept to industrial deployment," Robot. Comput. Integr. Manuf., vol. 37, pp. 282-291, 2016. 